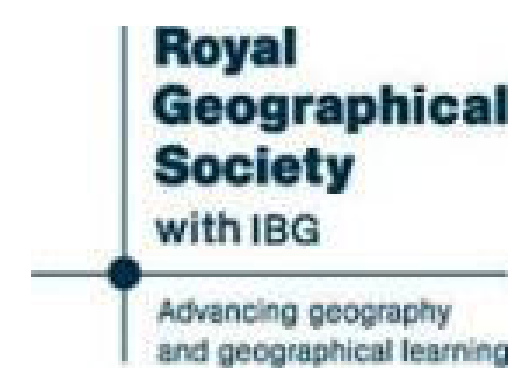

The Geographical Work of the United States Coast and Geodetic Survey Author(s): T. C. Mendenhall

Source: The Geographical Journal, Vol. 11, No. 3 (Mar., 1898), pp. 289-293

Published by: The Royal Geographical Society (with the Institute of British Geographers)

Stable URL: http://www.jstor.org/stable/1774682

Accessed: 15/12/2014 07:06

Your use of the JSTOR archive indicates your acceptance of the Terms \& Conditions of Use, available at

http://www.jstor.org/page/info/about/policies/terms.jsp

JSTOR is a not-for-profit service that helps scholars, researchers, and students discover, use, and build upon a wide range of content in a trusted digital archive. We use information technology and tools to increase productivity and facilitate new forms of scholarship. For more information about JSTOR, please contact support@jstor.org. 
estimates of others whom she quotes (vol. i. p. 82). The total population is generally taken by her at $12,000,000$, and in one place she puts it down as $12,000,000$ to $14,000,000$. The following are census returns or estimates of town populations: Seul, " by a careful census taken in February, 1897," intra-mural, 144,636 ; extra-mural, 75,189; total, 219,825-males predominating to the extent of 11,079 ; Pyeng-yang (the Phyöng-yang of Mrs. Bishop and of Mr. Carles in Proceedings, 1886, p. 300, the Pingyang of the newspapers at the time of the war) before the war, 60,000 (Mr. Carles, above 20,000; Mr. Campbell in the Proceedings, 1892, p. 157, probably 100,000), at the time of Mrs. Bishop's visit, one year after the battle fought close by, 15,000; * Hwang-ju before the war, 30,000, now 5000-6000; Song-do or Kai-seng, 60,000; Chemulpo, a foreign population in January, 1897, of 4357 (3904 Japanese, 404 Chinese), estimated Korean population, 6756 ; Fusan, foreign, January, 1897, 5564 (nearly all Japanese), estimated Korean population of city and prefecture of Tung-nai, 33,000; Wensan, foreign (mainly Japanese) in January, 1897, 1357, estimated Korean, 15,000.

With regard to the other contents of the volumes, there is only space to mention that there are chapters on Korean customs, history, government, education, finance, and superstition ; on Christian missions ; some pages on trade well worth the attention both of British statesmen and British merchants; and four chapters on Manchuria at the time of the outbreak of the Japo-Chinese war, besides appendices.

Mrs. Bishop has evidently taken pains with the spelling of proper names. Her Korean spellings are mainly in agreement with those of Mr. Carles in the paper in the Proceedings above cited, though her Whang-ju is hardly an improvement on his Hwang-ju. These I have not been able to follow, as not being in agreement with the present rules of the Society, and I have altered them in accordance with the map or text of Mr. Campbell's paper in the Proceedings for 1892. The Russian names are unfortunately rendered in German forms, and Vladivostok appears under the curious hybrid form of Wladivostok.

\section{THE GEOGRAPHICAL WORK OF THE UNITED STATES COAST AND GEODETIC SURVEY. $\dagger$}

By T. C. MENDENHALL, formerly Superintendent of the Coast and Geodetic Survey; and OTTO H. TITTMANN, Assistant in Charge of the Office of the Survey.

WHILE a relatively small part of the energies of the United States Coast and Geodetic Survey has been devoted, since the creation of the Bureau in 1807, to geographical exploration, it is, perhaps, only just to say that in the character and

* " Four-fifths of its houses destroyed, streets and alleys choked with ruins, hillslopes and vales, once thick with Korean crowded homesteads, covered with gaunt hideous remains" (vol. ii. p. 114).

† Read before Section E (Geography) at the Toronto Meeting of the British Association, August, 1897. 
amount of its precision work it is second to no similar organization in the world. From the very start the standard of work has been the highest attainable in the existing condition of the arts and sciences on which such work must depend, and often, not content with that condition, the Survey has made it its business to better it by original investigations of the first class, leading to improvements in the instruments and methods of the highest importance. It thus became the principal, and for many years almost the only, bureau of the government in which exact science was cultivated. In its outward activities it was essentially an organization for the practical application of science to the solution of certain problems and the issue of certain publications which were of the utmost value to commerce.

The duties to be performed by it were to sound the depths of the ocean along the coasts of the United States, to define the shallows which barred the ways of commerce, to delineate with great accuracy the shores and physical condition of the thousand harbours and estuaries with which a benign Providence has blessed our coasts, to investigate the tides and currents of the waters which bear their precious burden of human lives and property to and fro, and to study the mysterious variations and uncertainties of the magnetic needle by which the course of the navigator was largely directed.

To these immediate problems the Survey addressed itself with vigour and foresight under the guiding hands of Hassler and his eminent successors. Hassler, the friend of Jefferson and Gallatin, enjoyed the confidence and support of these eminent statesmen, but he had before him difficulties as great as his field was wide. Inert public opinion as to the utility of the proposed survey had to be vitalized and moulded, men had to be trained to carry out the technical parts of the work, instruments had to be constructed, and correct methods had to be prescribed. How these difficulties presented themselves, and how they were overcome, will form a proper chapter, not only in the history of the great Survey which yet remains to be written, but also a chapter in the history of the progress of science in this country. It may be said that Hassler, in 1844, saw the fruition of his hopes when a general plan of operations prescribed by him was adopted by a scientific commission composed of army and navy officers and civilians. Its adoption marks the official recognition of the necessity for precise and systematic work in the mapping of our domain; its simple and correct outline of the operations to be followed in making a survey of great extent, has permitted the extension of the work in a manner commensurate with the enlargement of our national domain by acquisitions of territory from France, Spain, and Mexico. With the expansion of territory came the extension of the scope of the Survey, and finally, when the advantages of a transcontinental triangulation became apparent, its geodetic function was recognized by law. In accordance with its primary duties, the Survey has developed and charted the depth of the waters along our coasts with extreme minuteness and accuracy, not only in the rivers, bays, and harbours, but off shore as far as the needs of commerce demanded it. Going beyond the immediate requirements of the mariner, it devoted itself to discovering the depths of the sea over large areas, as is shown by the complete survey of the Gulf of Mexico. Its depths were sounded and charted, its salinity tested, and the temperatures of its waters were recorded. Much earlier than these successful surveys of the gulf were the explorations of the Gulf Stream, important not alone in their geographical results, but in developing methods, often by failures, which rendered subsequent success possible. The hydrographical results achieved are shown on between five hundred and six hundred cbarts, many of them of such exquisite perfection as toform a standard of excellence for all cartographers. 
Its researches in physical hydrography include not only the study of the tides and currents, and incidentally the establishment of planes of reference from which the constancy of the relation between the ocean-level and the land is to be inferred, but it has studied for future comparison the movements of sandy shores, as, for instance, those of Cape Cod and of the exposed islands of Nantucket and Martha's Vineyard, to discover the relationship between the outlying shoals and the changes of the shores. Here again precision of work alone is of any avail, for correct conclusions can only be drawn after the lapse of time and after a standard of comparison has been created by an accurate survey. Want of space forbids the enumeration of many special results, but the discovery of the value of the tidal circulation through the East river as a factor in maintaining the depth of the bar at Sandy Hook, and the discovery of the underrun of the Hudson and its bearing on the feasibility of obtaining a water-supply for the towns along that river, may be mentioned as contributions in a special field of geography.

As properly belonging to the subject of the hydrographical surveys, the literature of the several and successive volumes of the 'Coast Pilots,' published by the Survey, must be mentioned. The 'Coast Pilots' of Alaska, compiled by Davidson, and later by Dall, are invaluable historical records of the geography of that coast, and the same may be said of the volumes covering the remainder of the Pacific coast, and those which describe in detail our Atlantic shores. 'They are not intended to deal in generalities, but they describe with rigid particularity geographical landmarks which are to guide ships by ciay and by night.

The maps of the Survey are embellished by accurate representation of the topography which borders our shores. For thousands of miles a narrow fringe of topography has been mapped with minute and necessary accuracy. It is based on local and detailed triangulation, which in turn rests on a larger network of triangles, which co-ordinates all the surveys along the coasts.

The introduction of precise methods for the determination of latitudes and longitudes went hand-in-hand with all the other operations of the Survey. Thus the success of Morse in the spring of 1844 was followed in the autumn of the next year by formal instructions given by Bache to Walker to prepare for telegraphic longitude determinations, but it was not until October 10, 1846, that the method was successfully put into practice by the exchange of signals between Philadelphia and Washington, and thereafter the precise determination of longitudes had merely to await the extension of the telegraph system from point to point within our own borders and throughout the world. As soon as the Atlantic cable had been laid in 1866 , the Survey successfully undertook to determine our longitude from Greenwich by the telegraphic method. Up to that time the longitude adopted for Cambridge, Massachusetts, in 1851, was used. The adopted value, $4^{\mathrm{h}} 44^{\mathrm{m}} 29 \cdot 5^{\mathrm{s}}$, had been derived from many years of laborious observations of moon culminations, eclipses, occultations, and chronometer determinations; but this value was increased (in 1869 ) by $1.35^{\mathrm{s}}$, as the result of comparatively brief cable determinations. Similarly, the longitude adopted for San Francisco, in 1855, as the result of 206 moon culminations, was increased in 1869 by $3 \cdot 1^{\mathrm{s}}$-in linear measure, about three-quarters of a mile-by the telegraphic determination. Within the last year, the Survey has completed and adjusted its primary longitude-net, covering the whole United States, and fixing for all time the astronomical longitudes of the points included in it, not only in their relation to each other, but in all probability their final relation to the initial meridian of Greenwich, since in this adjustment three transatlantic determinations by the Coast Survey, and one by the Canadians, have been used. Less need be said of the many latitude determinations, since the methods adopted, though admirable in their precision, involved no such radical 
improvement as that which the telegraph brought about in the determination of longitudes. On the other hand, however, the zenith telescope, as developed by the Survey, has, in the hands of its observers, contributed materially to our knowledge of the variation of latitude.

Reference has been made to the geodetic function of the Survey. It has measured an oblique arc, the last triangles in which have but just now been observed, extending from the north-eastern boundary to the Gulf of Mexico. To join this with the primary chain, as yet incomplete, of triangles along the Pacific coast, a great arc has been measured along the 39th parallel of latitude, the completion of which has been but recently announced.

The adjustment of the triangulation along this great arc, and the adoption of a homogeneous system of geographical co-ordinates, will furnish the fundamental data for the co-ordination of all government or state surveys for all time to come, if it be permitted to fallible human wisdom to make such an assertion. Grand in its inception, splendid in its execution, this monumental work may be reckoned as the most important contribution to the geography of our country, on account of its present and prospective value. The measurement of a great meridional arc along the 98th meridian is in contemplation, and our sister Republic of Mexico, which has just established a Geodetic Survey, it is hoped will take a band in its extension southward, while to our cousins across the northern border a similar opportunity for its prolongation northward may be offered in the course of time.

The Survey has been especially called upon for assistance in defining the boundaries of eleven states, and aid has been extended to fifteen more by the determination of geographical positions within their borders. In the determination of the national boundaries, it has co-operated in retracing the line between Mexico and the United States, has made topographical surveys along the north-eastern boundary, and in the far north it has determined the crossing of the 141st meridian on the Porcupine and Yukon rivers, in regions to which all adventurous eyes are now turned, and in South-East Alaska it has made exploratory surveys as well as precise geographical determinations for the ultimate delineation of the boundary between Alaska and the British possessions.

The enormous extent of the country included in the operations of the Survey, and especially its nearness to the principal north magnetic pole, offered a rare opportunity for the investigation of the problem of terrestrial magnetism. Observations began at an early date, and have been continued up to the present time, at a constantly increasing number of stations. In addition to a regular periodical study of the magnetic elements at a large number of specially selected points, by the most approved methods and the best of instrumental appliances, the Survey has maintained a photographic registering magnetic observatory, which it has moved, from time to time, from one part of the country to another. It bas made extensive publication of the data thus obtained, including a series of magnetic charts, which are of the greatest value to navigators at sea and surveyors on the land. Its archives contain a mass of reliable information concerning terrestrial magnetism unequalled in extent and importance.

In common with several similar organizations in Europe, it has devoted much attention, mostly during the past twenty-five years, to the study of terrestrial gravity. Beginning with rnethods long in use, its observers were quick to detect and point out certain serious and hitherto unsuspected faults, necessitating considerable corrections in nearly all accumulated data relating to that subject.

Instruments were also improved and methods greatly changed, increasing at once the precision and rapidity of gravity measurements. Expeditions have been sent to various quarters of the globe for the purpose of gravity observations, and 
Coast Survey pendulums have swung in all continents except Australia, in most important cities, on several of the highest mountains, and on many islands in the several oceans. No others bave been vibrated so near the pole as these, and none over so wide a range in longitude. The results of these operations, together with the measurement of the great arc of unrivalled length, form a contribution of no ordinary interest to the more precise solution of the great problems of dimensional geography.

\section{THE TREATY WITH ABYSSINIA.}

The only boundary referred to in Mr. Rennell Rodd's treaty with the Emperor Menelek is that of British Somaliland, and this has been settled in the spirit of mutual concessions. The agreements made with France on February 1, 1888, and Italy on May 5, 1894,* are not affected by this new settlement. The boundary, as now finally settled, begins at the well of Hadu, between Jibuti, the rising capital of "French Somaliland" and Zeila, follows the caravan route as far as Abasuen and the hill of Sumadu, and then continues in a south-south-west direction up to

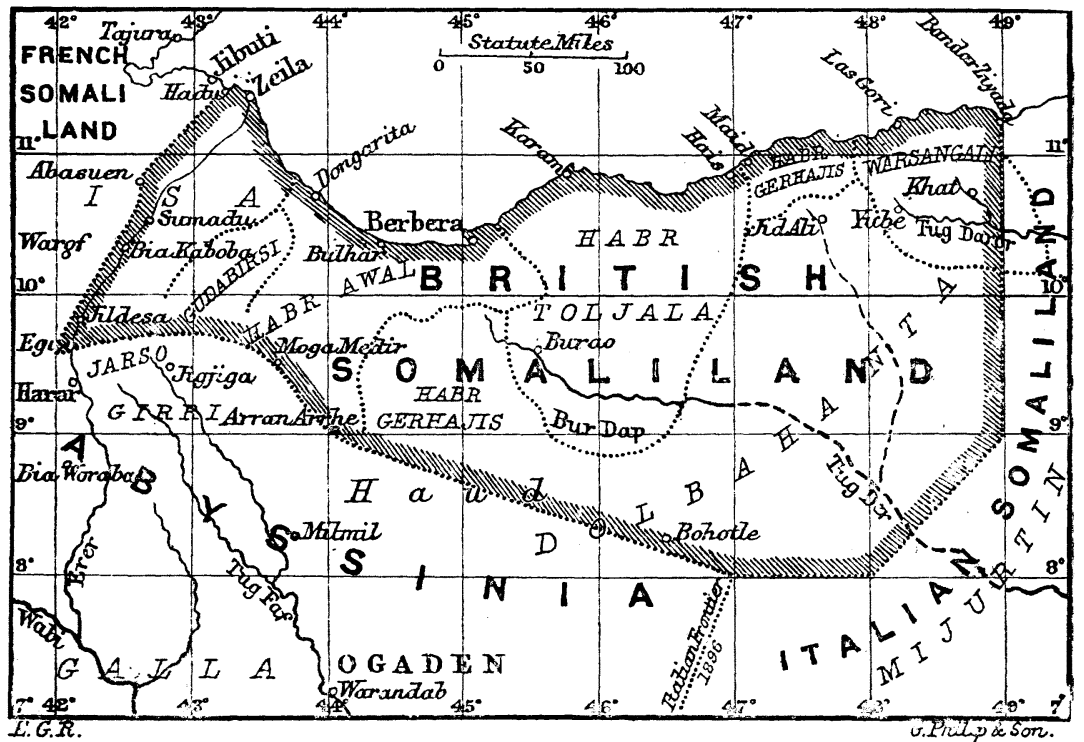

the pass above Egu, which lies only 10 miles to the north of Harar, at an elevation of 7500 feet above the sea. Thence it turns abrupily to the east, leaving the northern slope of the mountains with Britain. At Moga Medir ("Moga's eyetooth"), a beap of rock concerning which Burton tells us a pretty legend, the boundary turns to the south-east, passing tho ough Eylinta Kaddo to Arran Arrhe, near the intersection of the 9 th parallel with the 44 th meridian. From this point

* See Geographical Journal, vol. iv, 1894, p. 56.

No. III.-MARCH, 1898.] 